Center of Columbia University, New York. We thank the midwives, health visitors, general practitioners, medical records officers, and clinicians who provided essential information and also the children and their parents.

1 Cooper JE. Epilepsy in a longitudinal survey of 5000 children. BMf 1965;i $1020-2$

2 van den Berg BJ, Yerushalmy J. Studies on convulsive disorders in young children. I. Incidence of febrile and nonfebrile convulsions by age and other factors. Pediatr Res 1969;3:298-304

3 Ross EM, Peckham CS, West PB, Butler NR. Epilepsy in childhood: findings from the national child development study. BMF 1980;280:207-10

4 Ellenberg JH, Hirtz DG, Nelson KB. Age at onset of seizures in young children. Ann Neurol 1984;15:127-34

5 Chamberlain R, Chamberlain G, Howlett B, Claireaux A. British births 1970. Vol 1. The first week of life. London: William Heinemann, 1978.

6 Verity CM, Butler NR, Golding J. Febrile convulsions in a national cohor followed up from birth. I. Prevalence and recurrence in the first five years of life. $B M 7$ 1985;290:1307-10

7 Verity CM, Butler NR, Golding J. Febrile convulsions in a national cohort followed up from birth. II. Medical history and intellectual ability at 5 years of age. BMF 1985;290:1311-5.

8 Verity $\mathrm{CM}$, Golding J. Risk of epilepsy after febrile convulsions: a national cohort study. BMF 1991;303:1373-6.

9 The Commission on Classification and Terminology of the International League Against Epilepsy. Proposal for revised clinical and electroencephalographic classification of epileptic seizures. Epilepsia 1981;22:489-501.

10 Nelson KB, Ellenberg JH. Predictors of epilepsy in children who have experienced febrile seizures. N Engl f Med 1976;295:1029-33.

11 Sander JWAS, Shorvon SD. Incidence and prevalence studies in epilepsy and their methodological problems: a review. I Neurol Neurosurg Psychiatr 1987;50:829-39.

12 Shorvon SD. The temporal aspects of prognosis in epilepsy. $f$ Neurol Neurosurg Psychiatry 1984;47:1 157-65.

13 Chadwick D. Epilepsy after first seizures: risks and implications. 7 Neurol Neurosurg Psychiatry 1991:54:385-7.
14 Hart Y.M, Sander JWAS, Johnson AL, Shorvon SD, for the NGPSE. National general practice study of epilepsy: recurrence after a first seizure. Lancel 1990;336:1271-4.

15 Hauser WA, Rich SS, Annegers JF, Anderson VE. Seizure recurrence after a first unprovoked seizure: an extended follow-up. Neurology 1990;40: $1163-70$

16 Berg AT, Shinnar S. The risk of seizure recurrence following a first unprovoked seizure: a quantitative review. Neurology 1991;41:965-72.

7 Goodridge DMG Shorvon SD. Epileptic scizures in a population of 6000. Demge DMG Shorun SD. Epile Demography, diagnosis,

18 Goodridge DMG, Shorvon SD. Epileptic seizures in a population of 6000 . II Treatment and prognosis. BMF 1983;287:645-7.

19 Chevrie JJ, Aicardi J. Convulsive disorders in the first year of life: neurological and mental outcome and mortality. Epilepsia 1978;19:67-74.

0 Chevrie JJ, Aircardi J. Convulsive disorders in the first year of life: persistence of epileptic seizures. Epilepsia 1979;20:643-8.

21 Cavazutti GB, Ferrari P, Lalla M. Follow-up study of 482 cases with convulsive disorders in the first year of life. Dev Med Child Neurol 1984;26:425-37.

22 Falconer MA, Serafetinides EA, Corsellis JAN. Etiology and pathogenesis of temporal lobe epilepsy. Arch Neurol 1964;10:233-48.

23 Taylor DC, Ounsted C. Biological mechanisms influencing the outcome of seizures in response to fever. Epilepsia 1971;13:33-45.

farbrough FW, Hauser WA, An factors for generalized tonic-clonic seizures: a population-based case-control Roca WA, Sharbroug FW, Hauser WA, Annegers J15-22.

choenberg BS. Risk factors for complex partial seizures: a population-based case-control study. Ann Neurol 1987;21:22-31.

26 Annegers JF, Shirts SB, Hauser WA, Kurland LT. Risk of recurrence after an initial unprovoked seizure. Epilepsia 1986;27:43-50.

27 Annegers JF, Hauser WA, Elveback LR. Remission of seizures and relapse in patients with epilepsy. Epilepsia 1979;20:729-37.

28 Sillanpaa M. Medico-social prognosis of children with epilepsy. Acta Paediatr Scand 1973;Suppl 273:1-104

(Accepted 20 August 1992)

\title{
Cost implications of the British Pacing and Electrophysiology Group's recommendations for pacing
}

\author{
M A de Belder, N J Linker, Sue Jones, A J Camm, D E Ward
}

Abstract

Objective-To compare present pacing practice with the recommendations recently published by the British Pacing and Electrophysiology Group and to assess the increase in annual budget required to implement these recommendations in a regional cardiothoracic unit.

Design-Retrospective analysis of pacemaker implantation for 1991 with calculation of the costs required to implement the group's recommendations based on average 1991 costs of the types of pacing generators and electrode leads used.

Setting-Regional cardiothoracic unit for South West Thames Health Authority.

Patients-433 consecutive patients receiving permanent pacemaker generators: $76(18 \%)$ with sinus node disease; $270(62 \%)$ with atrioventricular block; $25(6 \%)$ with both sinus node disease and atrioventricular block; $59(14 \%)$ with chronic atrial fibrillation and atrioventricular block; and $3(1 \%)$ with carotid sinus or malignant vasovagal syndromes.

Results-Only $102(24 \%)$ patients received pacemaker generators recommended by the British Pacing and Electrophysiology Group; however, 355 $(82 \%)$ patients were older than 65 years, and 264 $(61 \%)$ were aged 75 or over. The cost of hardware for pacing was $£ 462885$. Using generators as recommended would have cost $£ 810525$ for "optimal" systems (an increase of $75 \%$ ) and $£ 710750$ for "alternative" systems (an increase of 54\%). These increases would have been considerably reduced by limiting the use of sophisticated pacing to younger patients (aged under 75). Further savings could be made by using the least expensive pacing models available.

Conclusions-Implementing these recommenda- tions should reduce morbidity related to bradyarrhythmia but will lead to major increases in pacing costs. Age and patients' expected activity may be used to select simple pacing systems and thus to contain cost. More research is needed to determine which patient groups will benefit most from complex pacing systems.

\section{Introduction}

The British Pacing and Electrophysiology Group has recently published its recommendations for pacemaker prescription for symptomatic bradycardia. ${ }^{1}$ Its report discussed three pacing "policies": right ventricular demand (VVI) pacing for everyone (which was deemed inappropriate); the routine use of the most $\tilde{N}$ sophisticated system appropriate for the patients' I needs (acceptable but costly); and careful prescription along the recommendations of the report. The working party acknowledged that a radical change in practice would be needed in some pacing centres. Additional funding would also be required for more widespread use of dual chamber and rate responsive pacing systems and their follow up. The extent of the additional funding required is unknown but depends on the prevalence of the different electrocardiographic diagnostic groups (as used by the British Pacing and Electrophysiology Group) in the general population. Table I shows the recommended systems.

Many centres, ours included, at present use far more single electrode ventricular (VVI) pacing systems than is suggested by these recommendations. Although the British Pacing and Electrophysiology Group accepted that these systems might suffice for atrioventricular block in the face of terminal disease or conditions that reduce mobility (for example, previous hemiplegia), most centres use these modes predominantly in elderly 
patients. The report did not, however, mention age as a particular factor to be used in selecting a system. The other major factor that has been important in the continued use of simple single chamber systems is cost. We investigated the prevalence of the diagnostic groups in patients paced in our unit during 1991 and evaluated the cost implications of these recommendations for our unit.

\section{Patients and methods}

At the beginning of 1992 we analysed the records of all patients who had undergone pacing procedures in our unit in 1991. All patients receiving their first implant or a change of generator were included in the study. Patients who received new implants relating to a complication of a system implanted earlier in 1991 were excluded (that is, only the first implantation was included in the analysis). From the records we determined the age and sex of the patient, the reason for pacing, and the pacing system used.

The average costs for single chamber, single chamber rate responsive, dual chamber, and dual chamber rate responsive systems were calculated on the basis of the range of systems used at our centre. These costs were then used to determine the cost of pacing our patients according to the British Pacing and Electrophysiology Group's recommendations. The costs of using the least expensive systems available to us for all patients were also calculated. The data were reanalysed after the patients were arbitrarily split into two groups: an elderly group (aged 75 or over) in whom only simple ventricular pacing would be used and a younger group in whom pacing would be as recommended by the report. The British Pacing and Electrophysiology Group's database for 1990 and 1991 was examined to investigate the ages of patients paced in the United Kingdom and to ascertain the prevalence of certain electrocardiographic diagnostic groups.

\section{Results}

During 1991, 433 patients received pacemaker generators in our unit, 246 of whom $(57 \%)$ were male. The mean (SD) age was 75 (12) years, range 21-96 years. The figure shows the age of patients. The data for our unit were compared with the data from the British Pacing and Electrophysiology Group's register for 1990 and 1991. No paediatric pacing is undertaken in our unit, and although the distribution was similar for the register and our unit, proportionately more of our patients were in the older age groups. In the register $56 \%$ of patients were aged 75 or older compared with $61 \%$ of our patients (difference not statistically significant)

Table II shows the different electrocardiographic diagnostic groups in our unit. These data cannot be compared with the overall data in the British Pacing and Electrophysiology Group's register, which allows only one electrocardiographic diagnosis for each

TABLE I-Pacing modes recommended by the British Pacing and Electrophysiology Group

\begin{tabular}{|c|c|c|c|c|}
\hline \multirow[b]{2}{*}{ Diagnosis } & \multicolumn{2}{|l|}{ Optimal } & \multicolumn{2}{|l|}{ Alternative } \\
\hline & $\begin{array}{l}\text { Single (site) or } \\
\text { dual chamber electrode }\end{array}$ & $\begin{array}{l}\text { Rate } \\
\text { response }\end{array}$ & $\begin{array}{l}\text { Single (site) or } \\
\text { dual chamber electrode }\end{array}$ & $\begin{array}{l}\text { Rate } \\
\text { response }\end{array}$ \\
\hline Sinoatrial node disease & Single $(A)$ & Yes & Single (A) & No \\
\hline Atrioventricular block & Dual & No & Dual & No \\
\hline $\begin{array}{l}\text { Sinoatrial node disease plus } \\
\text { atrioventricular block }\end{array}$ & Dual & Yes & Dual & No \\
\hline $\begin{array}{l}\text { Chronic atrial fibrillation plus } \\
\text { atrioventricular block }\end{array}$ & Single $(V)$ & Yes & Single $(V)$ & No \\
\hline Carotid sinus syndrome & Dual & No & $\begin{array}{c}\text { Dual } \\
\text { Single }(V)\end{array}$ & $\begin{array}{l}\text { No } \\
\text { No }\end{array}$ \\
\hline Malignant vasovagal syndrome & Dual & No & Dual & No \\
\hline
\end{tabular}

$\mathrm{A}=$ electrode positioned in right atrium; $\mathrm{V}=$ electrode positioned in right ventricle.

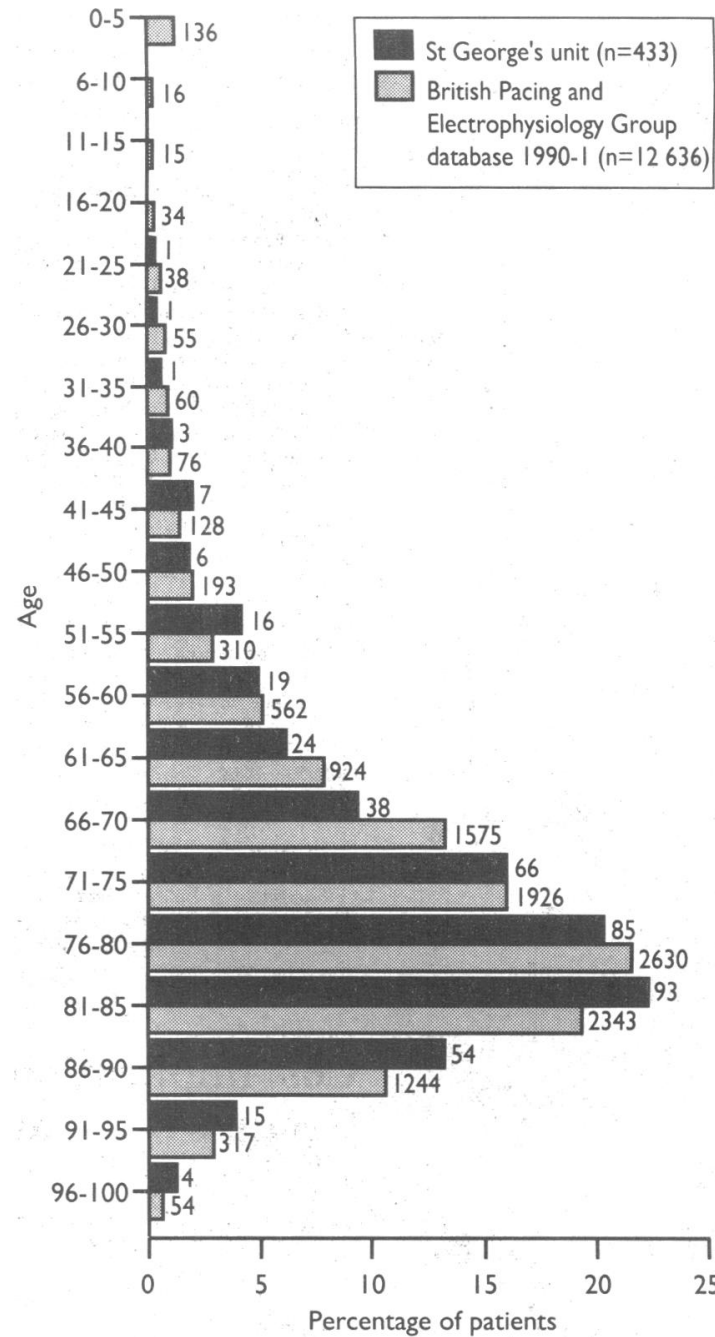

Frequency of patients paced by age: data in our unit (black columns $n=433$ ) compared with the data from the British Pacing and Electrophysiology Group's Database (grey columns, $n=12636$ ) from 1990 and 1991

TABLE II-Diagnostic groups of patients paced in 1991

\begin{tabular}{lcc}
\hline Diagnosis & No (\%) of patients & $\begin{array}{c}\% \text { In } \\
\text { "typical" } \\
\text { centre }\end{array}$ \\
\hline $\begin{array}{l}\text { Sinoatrial node disease } \\
\begin{array}{l}\text { Atrioventricular block } \\
\text { Sinoatrial node disease plus } \\
\text { atrioventricular block }\end{array}\end{array}$ & $76(18)$ & 25 \\
$\begin{array}{l}\text { Chronic atrial fibrillation plus } \\
\text { atrioventricular block }\end{array}$ & $25(6)$ & 42 \\
$\begin{array}{l}\text { Carotid sinus syncope } \\
\text { Malignant vasovagal syndrome }\end{array}$ & $59(14)$ & 10 \\
& $1(<1)$ & 13 \\
\end{tabular}

*As found by British Pacing and Electrophysiology Group

patient. Thus it was not possible to determine the prevalence of patients with both sinus node disease and atrioventricular block. The group's database identified no patients as being paced for carotid sinus syndrome or the malignant vasovagal syndrome, presumably because they were classified as "unspecified" or some other category. From the group's register we determined that for 1990 and $1991,21 \%$ of patients were paced for sinoatrial node disease, $49 \%$ were paced because of various categories of atrioventricular block, $12 \%$ were paced for chronic atrial fibrillation or flutter with atrioventricular block, and $18 \%$ had various other electrocardiographic diagnoses.

Table III shows our use of each type of pacemaker unit. Our use of dual chamber systems was $12 \%$ overall, although it was $28 \%(47 / 169)$ in patients aged under 75 , compared with $3 \%(7 / 264)$ of those aged 75 or over. Had the group's recommendations been 
TABLE III-Pacemaker generators used in 1991

\begin{tabular}{lccc}
\hline \multicolumn{1}{c}{ Unit } & & \\
$\begin{array}{lccc}\text { Pacing } \\
\text { code }\end{array}$ & $\begin{array}{c}\text { Single (site }{ }^{\star} \text { ) or } \\
\text { dual chamber electrode }\end{array}$ & $\begin{array}{c}\text { Rate } \\
\text { response }\end{array}$ & $\begin{array}{c}\text { No }(\%) \text { used } \\
(\mathrm{n}=433)\end{array}$ \\
\hline AAI & Single (A) & No & 0 \\
AAIR & Single (A) & Yes & $1(0 \cdot 2)$ \\
VVI & Single (V) & No & $340(78 \cdot 5)$ \\
VVIR & Single (V) & Yes & $38(8 \cdot 8)$ \\
DDD & Dual & No & $37(8 \cdot 5)$ \\
DDDR & Dual & Yes & $17(3.9)$ \\
\hline
\end{tabular}

* $\mathrm{A}=$ electrode positioned in right atrium; $\mathrm{V}=$ electrode positioned in right ventricle.

TABLE IV-Average costs of pacing systems used

\begin{tabular}{|c|c|c|c|c|}
\hline \multirow[b]{2}{*}{ Unit } & \multicolumn{3}{|c|}{$\operatorname{Cost}(£)$} & \multirow{2}{*}{$\begin{array}{l}\text { Total cost }(£) \text { of least } \\
\text { expensive system (1991) }\end{array}$} \\
\hline & Generator & Electrode & Total & \\
\hline \multicolumn{5}{|c|}{ Single chamber electrode ( $A$ or $\mathrm{V})$ : } \\
\hline No rate response & 700 & 150 & 850 & 635 \\
\hline Rate response & 1365 & 150 & 1515 & 835 \\
\hline \multicolumn{5}{|c|}{ Dual chamber electrodes (A and V): } \\
\hline No rate response & 1650 & 350 & 2000 & 1520 \\
\hline Rate response & 2050 & 350 & 2400 & 1620 \\
\hline
\end{tabular}

$\mathrm{A}=$ electrode positioned in right atrium; $\mathrm{V}=$ electrode positioned in right ventricle.

TABLE V-Actual versus estimated costs $(£)$ of pacing

\begin{tabular}{ccc}
\hline & \multicolumn{2}{c}{$\begin{array}{c}\text { Costs (budget increases) using the recommendations of } \\
\text { British Pacing and Electrophysiology Group }\end{array}$} \\
\cline { 2 - 3 } Actual cost 1991 & Optimal systems & Alternative systems \\
\hline 462885 & $810525(75 \%)$ & $710750(54 \%)$ \\
Estimated costs using least expensive pacing systems available in 1991 \\
332245 & $568185(71 \%)$ & $538685(62 \%)$ \\
\hline
\end{tabular}

followed, $298(69 \%)$ of our patients would have received dual chamber pacing systems, 25 of which would have been rate responsive.

According to the guidelines, only $102(24 \%)$ of our patients received appropriate pacing systems. Of the $331(76 \%)$ patients deemed to have received a suboptimal system, $218(66 \%)$ were aged 75 or over. Of the 169 patients aged under 75, $57(34 \%)$ were deemed to have received appropriate systems. On reanalysis of our data on the assumption that it was "appropriate" to pace patients aged 75 or over with the simplest (VVI) mode regardless of the diagnosis, 321 of 433 patients $(74 \%)$ would have received appropriate pacing systems.

Table IV shows the average costs of the pacing systems used in 1991. The total cost of pacing hardware used for the 433 patients was $£ 462885$. Had we used only the least expensive model available to us for each diagnostic group (see table IV), the costs could have been reduced to $£ 332245$, a saving of $28 \%$ (see table V). Using the "optimal" recommended system in all cases would have cost $£ 810525$, an increase of $£ 347640(75 \%)$ on our present budget. If only the least expensive generators available had been used the extra cost would have been $£ 105300$, an increase of $23 \%$ on the $£ 462885$ actually spent; this represents a $71 \%$ increase on the $£ 332245$ that would have been spent had we originally used only these systems. With the "alternative" recommended systems the cost would have been $£ 710750$, an increase of $£ 247865$ (54\%) on our actual expenditure. With only the cheapest generators, the cost increase would have been $£ 75800$ $(16 \%)$ on our actual budget; this represents a $62 \%$ increase on the $£ 332245$ that would have been spent had we originally used only these systems.

Hardware costs were reanalysed with the arbitrary ruling that all patients aged 75 or over should receive a simple ventricular system. The total hardware costs for 1991 would have been reduced by $£ 12705$ to $£ 450180$. With the optimal recommended system for all younger patients would have given total hardware costs of $£ 544210$; with the alternative systems recommended, the total costs would have been $£ 500300$.

\section{Discussion}

The recommendations of the British Pacing and Electrophysiology Group form the basis for providing patients with the most physiologically appropriate pacing system to treat their bradyarrhythmia. In addition, these pacing systems will minimise complications related to inappropriate pacing. These include the pacemaker syndrome, lack of physiological hear rate response to exercise, and spontaneous development of atrial fibrillation and systemic emboli. Th discrepancy between these recommendations and our pacing practice suggests that either there are pressing reasons not to apply them to individual cases or that th recommendations are unreasonable.

In our unit it is clear that age has been a major factor in determining the type of system used and, in particular, in determining the choice of the simple ventricular systems, which are inexpensive and easy to implant. Our data show that most of our patients are elderly. Although their age range in 1991 was from 21 to 96 years, $82 \%$ (355) were over 65 and $61 \%$ (264) were 75 or over. Many of these patients, although not severely infirm, have sedentary lifestyles, and unless we are impressed by their level of activity it has not been our policy to use dual chamber or rate responsive units for this group. Although our data show that proportionately more of our patients are in older age groups than are those in the British Pacing and Electrophysiology Group's database, the difference are not significant. We are certainly not advocating that age should be a sole or even major factor in determining which pacing system should be used. It would be inappropriate to deny many older patients the advant ages of more complex systems. However, considerable cost reductions may be achieved by minimising the use of complex systems in older patients.

Another limitation of the group's recommendations is their failure to distinguish between patients with intermittent and with chronic bradyarrhythmia. It has been argued that ventricular pacing, especially with hysteresis, is a highly satisfactory mode for patients with infrequent episodes of complete atrioventricular block associated with symptoms. ${ }^{2}$ Similarly, this pacing mode may not be inappropriate for patients with sinoatrial node disease and very infrequent symptoms; it is of note that $86 \%$ of patients with sick sinus syndrome on the group's database between 1980 and 1989 were paced with ventricular electrodes only. ${ }^{3}$ The recommendations are, however, based on evidence that the use of more atrial electrode or dual chamber systems will minimise complications and improve exercise capacity.

\section{SINGLE ELECTRODE VENTRICULAR SYSTEMS}

Several studies have shown an apparent increase in complications in patients with sinus node disease treated with a single electrode ventricular (VVI) system compared with those treated with a single atrial electrode (AAI) system. ${ }^{47}$ Although the evidence taken overall is compelling, many of these studies are flawed. None is a prospective randomised study, and in general the reasons for selecting different pacing modes are not documented or discussed. In the study by Rosenqvist and colleagues, for example, the patients treated with a ventricular system had bigger hearts; more had congestive failure; more had valve disease; and they were older than the patients treated with an atrial system. ${ }^{6}$ Similarly, in the study by Bianconi et al the patients treated with a ventricular pacemaker were older and had a longer follow up period than the group treated 
with an atrial system. ${ }^{5}$ The increased mortality and morbidity in the patients paced ventricularly may well relate to the underlying cardiovascular status and age of the patient rather than the pacing system selected. It is also interesting to note that smaller studies comparing about 50 patients in each group, such as that by Zanini and coworkers, ${ }^{8}$ have not shown any impact on mortality, suggesting that many patients may have to be paced in the "correct" mode to benefit a few. No studies have investigated these problems in relation to sinus node disease in patients older than 75 years, and the reported benefits may apply more to younger patients.

Another reason for using a venticular electrode in patients with sinus node disease is the fear that patients will also have underlying atrioventricular conduction disease, although this fear should prompt the use of dual chamber pacing modes rather than single electrode ventricular systems on theoretical grounds. The continued use of single electrode atrial pacing, however, is recommended on the grounds that the upgrade rate to dual chamber pacing is low. The development of significant atrioventricular block has been estimated at $0 \cdot 6 \%$ a year, with about $2 \%$ of patients requiring upgrade," although individual series have suggested an upgrade rate of up to $4.5 \%$ a year or a total of $12 \%$ of patients. Some of the variation may well reflect the different age groups of patients studied, as older patients are more likely to have concomitant atrioventricular conduction disease. Some investigators have reported a higher prevalence of atrioventricular conduction disturbance, which may reflect a large proportion of patients with associated cardiovascular abnormalities (hypertension, ischaemic heart disease, etc) or systemic conditions such as diabetes.

Although it is accepted that complications will occur more frequently if patients with significant atrioventricular block are paced with a single electrode ventricular system rather than with dual chamber synchronised pacing, ${ }^{1111}$ there is evidence to suggest that it is predominantly those with retrograde ventriculoatrial conduction who will have complications." Again, the impact of dual chamber as opposed to ventricular pacing alone in elderly patients has not been evaluated.

\section{DIAGNOSTIC GROUPS}

It is interesting that the "typical" pacing population highlighted in the British Pacing and Electrophysiology Group's report (taken from the statistics for City General Hospital, Stoke on Trent, 1986-9) includes $10 \%$ with carotid sinus and malignant vasovagal syndromes. Less than $1 \%$ of our patients had these diagnoses. These differences no doubt reflect differences in patient referral, but it is clear that an appreciable number of patients with unexplained syncope will suffer from these syndromes. ${ }^{13}$ Some of these patients, especially those with a dominant bradycardiac (as opposed to vasodepressor) component will benefit from dual chamber pacing.' Thus, should these patients be more thoroughly investigated, especially with tilt testing, more patients will be considered for dual chamber pacing systems, further adding to pacing costs. The occurrence of these syndromes in particular age groups is, however, unknown.

\section{COST AND OTHER IMPLICATIONS}

The costs calculated for our patients on the basis of the "optimal" recommendations show that introducing these guidelines for all patients would have a major impact on our budget, increasing annual hardware costs by $75 \%$. With the use of the "alternative" systems, we would still have to increase our budget by $54 \%$. By using the recommended systems only in a younger age group (those aged under 75 ) we could provide "complex" optimal systems in young patients (at the expense of theoretically suboptimal systems in elderly patients) at an increase in budget of only $18 \%$ (not allowing for inflation). Costs could be reduced by using only the cheapest generators available for each diagnostic group, but if our unit had used these generators in 1991 the British Pacing and Electrophysiology Group's recommendations would still havew resulted in substantial cost increases. Cost differencese reflect varying degrees of sophistication of generators, which provide theoretical and practical benefits fors? certain patients, and thus it is inappropriate to determine pacing costs based only on the least expen-음 sive generators available.

The more frequent use of dual chamber systems has certain implications other than that of cost. Staff haven to be trained to implant the atrial electrodes effectively. These systems take longer to implant than ventricular ${ }^{\circ}$ lead systems. Some groups advocate minimal electro- $\vec{\omega}$ physiological evaluation of patients with sinus nodeo disease (to investigate the possibility of covert atrio- $\frac{0}{3}$ ventricular conduction disease and to assess retrograde ventriculoatrial conduction), thus adding further to the time needed for pacemaker implantation. This hasis logistic implications for already extremely busy cardiacos catheter and pacing laboratories. We believe that these $e_{\infty}^{\infty}$ investigations are unnecessary, and that the choice of generator for each individual patient should be madeo before taking the patient to the laboratory for pacemaker implantation. The use of more dual chambero systems will also increase the workload of follow up? pacing clinics.

CONCLUSIONS

Adherence to the recommendations made by theed British Pacing and Electrophysiology Group would result in increased exercise capacity for patients anob minimisation of long term complications of pacing Whether these benefits apply to all age groups is noto known. In addition, the proportion of patients whő would escape disabling complications (especially pace-尺̊ maker syndrome and embolic events) is unknown. $\overrightarrow{\vec{F}}$ Moreover, it is clear that giving patients more complex systems than they receive at present will increase costs by $50-75 \%$. We have no reason to believe that mosp large cardiothoracic units do not adhere to policiess similar to our own, ${ }^{14}$ and thus the cost implications of the British Pacing and Electrophysiology Group's recommendations are potentially enormous on national scale. It is also clear that budgets for otherin cardiac services are stretched enormously, and it will not be possible to provide the increased budget needed for improvements in the pacing services by reducing these other services. More research on the benefits of complex pacing in different diagnostic and age group $\$$ is needed, and modifications to the recommendations. may be required. However, if the present evidence is supported and "appropriate" pacing is therefore tow become a reality additional funding will be needed.

1 Clarke M, Sutton R, Ward D, Camm AJ, Rickards A, Ingram A, et al Recommendations for pacemaker prescription for symptomatic bradycardiac Report of a working party of the British Pacing and Electrophysiology Group Br Heart f 1991;66:185-91.

2 Ahsan A. Indications for pacing Lancet 1992;339:62.

3 Ahsan AJ, Madden S, Rickards AF. Pacing for sinus node disease: prevalence and complications in the UK of different srimulation modes [abstractl Eur Hear $f 1990 ; 11: 300$.

Santini M, Alcida G, Porto MP, Santini A, Ammirati F, Ansalone G. Te sick sinus syndrome (SSS): prognosis as function of age, conduction defect and pacing mode [abstract]. PACE 1989;12:1237.

5 Bianconi L, Boccadamo R, Di Florio A, Carpino A, Catalano F, Stella C, et a Atrial versus rentricular stimulation in sick sinus syndrome: effects morbidity and mortality [abstract]. PACE 1989;12:1236.

6 Rosenqvist M, Brandt J, Schuller H. Long-term pacing in sinus node diseas effects of stimulation mode on cardiovascular morbidity and mortality Am Heart $\mathcal{1}$ 1988;116:16-2

7 Sasaki Y, Shimotori M, Akahane K, Yonekura H, Hirano K, Endoh R, et al. Long-term follow-up of patients with sick sinus syndrome: a comparison of clinical aspects among unpaced, ventricular inhibited paced, and physiologically paced groups. PACE 1988;11:1575-83. 
term follow-up of patients treated with 17 pacing and seyuential pacing with special reference to VA retrograde conduction. PACF 1988;11:1929-34 13 Fitzpatrick A, Theodorakis G, Vardas P, Kenny RA, Travill C.M, Ingram A et al. The incidence of malignant vasovagal ssndrome in patients with recurrent syncope. Fur Heart f 1991;12:389-94

14 Pacemakers-practice and paradex. Lancet 1991:338:1178-9.

\title{
The role of non-steroidal anti-inflammatory drugs in acute liver injury 市
}

\author{
Luis A García Rodriguez, Susanne Pérez Gutthann, Alexander M Walker, Leah Lueck
}

\begin{abstract}
Objective-To investigate the association between use of non-steroidal anti-inflammatory drugs and serious, acute non-infectious liver injury.

Design-Retrospective cohort study, cross over design.
\end{abstract}

Setting-Health records from provincial database in Saskatchewan, Canada, 1982-6.

Subjects-228392 adults who contributed 645456 person years. All were either using or had used nonsteroidal anti-inflammatory drugs.

Main outcome measures-Number and type of prescriptions for non-steroidal anti-inflammatory drugs. Admission to hospital for newly diagnosed acute liver injury.

Results-There were 34 admissions to hospital; 16 among subjects currently using non-steroidal antiinflammatory drugs and 18 among subjects who were not. The incidence rate among current users was 9 per 100000 person years $(95 \%$ confidence interval 6 to 15 per 100000 person years). Subjects currently using non-steroidal anti-inflammatory drugs had twice the risk of newly diagnosed liver injury as those not currently taking these drugs (rate ratio 2.3 ; $95 \%$ confidence interval 1.1 to 4.9 ) and an excess risk of 5 per 100000 person years. The age and sex adjusted risk ratio was $1.7(0.8$ to 3.7$)$. The strength of the association increased when only cases with no concomitant use of other hepatotoxic drugs were considered $(4.0 ; 0.9$ to 19.0$)$. The rate ratio for people having received one to nine prescriptions was constant. There was no increased risk with long duration of treatment $(1 \cdot 0 ; 0 \cdot 3$ to $3 \cdot 5)$.

Conclusions-There is a small excess risk of serious, acute non-infectious liver injury associated with the use of non-steroidal anti-inflammatory drugs.

Unit, Ciba-Geigy AG

Basel, Switzerland

Luis A Garcia Rodriguez, assistant professor

Susanne Pérez Gutthann, researcher

\section{Department of}

Epidemiology, Harvard

University School of Public

Health, Boston, USA

Alexander M Walker,

professor

GDS and Associates

Systems Ltd, Regina,

Canada

Leah Lueck, system analyst

Correspondence to:

Dr Garcia Rodriguez,

Boston Collaborative Drug

Surveillance Program,

Boston University Medical

Center, Lexington,

Massachusetts 02173, USA

BMF 1992;305:865-8
To provide additional information on the role of nonsteroidal anti-inflammatory drugs in acute liver injury we carried out a retrospective cohort study to evaluate the clinical features and incidence of acute noninfectious liver injury serious enough to require admission to hospital (with no other documented cause) in users of non-steroidal anti-inflammatory drugs by using the computerised databases of Saskatchewan Health in Canada. We also estimated the background $D$ incidence of admission for acute liver injury in the same population when they were not taking non- o steroidal anti-inflammatory drugs.

\section{Subjects and methods}

Over $95 \%$ of the 1.1 million residents of the province of Saskatchewan are entitled to receive medical benefits through the department of health. ${ }^{4}$ As a byproduct of providing these health services, the $\ddot{\oplus}$ Saskatchewan health plan has accumulated a large ! amount of medical care information on computerised databases over the past 20 years. This includes prescription data, outpatient and hospital diagnostic information, cancer and vital statistics, and records of special medical and supportive services. Most of these databases may be linked by a unique patient identifier. As a result a complete chronological profile of prescriptions, outpatient visits, and admissions to hospital is available for all patients included in the health plan. The population of the province is stable with low rates of immigration and emigration.

This study was part of a research project designed to look at the association between concurrent use of nonsteroidal anti-inflammatory drugs and several serious outcomes among the population from January 1982 to December 1986..$^{5}$ Any member of the health plan filling a prescription for one of five drugs (diclofenac, indomethacin, naproxen, sulindac, and piroxicam) N $N$ entered the study population and was followed up until $\rightarrow$ admission to hospital for hepatitis, death, departure from the health plan, or end of the study period.

The methods for classifying person time have been $\mathrm{N}$ presented in detail elsewhere. ${ }^{5}$ Briefly, subjects were categorised into current use of non-steroidal antiinflammatory drugs, which included the 60 days after a prescription, or no current use, which included all the remaining eligible person time of observation. Current use was further classified according to the most recent 0 drug dispensed. Every prescription filled after the $\mathbb{\mathbb { D }}$ patient became a study member was identified. During the study 12 non-steroidal anti-inflammatory drugs were available only through prescription, and aspirin was available over the counter. Subjects could pass 8 back and forth between the categories of use, determined by the dates on which the drugs were dispensed.

Periods of current use of non-steroidal anti-? inflammatory drugs were categorised according to the total preceding number of consecutive prescriptionsthat is, prescriptions that followed within 90 days of 